\title{
Applying dynamic mold temperature control to cosmetic package design
}

\author{
Shih-Wen Hsiao ${ }^{1}$, Chih-Huang Yen ${ }^{1, *}$, and Chu-Hsuan Lee ${ }^{1}$ \\ ${ }^{1}$ National Cheng Kung University, Industrial Design Department, 701, Tainan, Taiwan
}

\begin{abstract}
Owing to the fashion trend and the market needs, this study developed the eco-cushion compact. Through the product design and the advanced process technology, many issues have improved, for instance, the inconvenience of transportation, the lack of multiuse capability, the increase of costs, and the low yield rate. The eco-cushion compact developed in this study was high quality, low cost, and meets the requirements of the eco market. The study aimed at developing a reusable container. Dynamic mold temperature control was introduced in the injection modeling process. The innovation in the product was its multi-functional formula invention, eco-product design, one-piece powder case design, and multifunctional design in the big powder case, mold flow and development of dynamic mold temperature control. Finally, through 3D drawing and modeling, and computer assistance for mold flow and verification to develop and produce models. During the manufacturing process, in order to solve the problems of tightness and warping, development and manufacture of dynamic mold temperature control were introduced. This decreased the injection cycle and residual stress, and deformation of the products has reduced to less than $0.2 \mathrm{~mm}$, and the air tightness increased. In addition, air leakage was less than $2 \%$ and the injection cycle decreased to at least $10 \%$. The results of the study can be extended and applied on the future design on cosmetic package and an alternative can be proposed to solve the problems of air tightness and warping. In this study, dynamic mold temperature control is considered as a design with high price-performance ratio, which can be adopted on industrial application for practical benefit and improvement.
\end{abstract}

\section{Introduction}

In a prosperous economy and aging society, the aspects of using cosmetic spread rapidly. Skin aging is an inevitable biological phenomenon of human life. Advancing age brings changes to all components of the integumentary system with consequent signs on the skin. Skin aging is mainly due to intrinsic (chronologic) and extrinsic aging (photo-aging). Photo-aging is a consequence of exposure to ultraviolet radiations [8]. People use cosmetic to secure the aging problem, and global cosmetic markets are increasing annually.

Figure 1 presents the data announced by international market research resource, Research and Market [5] indicating that the turnover of 2014 in the global cosmetic market was 46 billion US dollars in 2014 and it will grow to 67 billion US dollars in 2020. The annual growth rate is around $6.4 \% \ldots$ Table 1 presents cosmetic categorization. Liquid foundation is a product combing water and power applied to the face to create an even color to the complexion, and to look pretty. Moreover, it is also a base layer for more complex cosmetics. The product was first introduced in 1937, and since then it has been a favor for female customers. However, the traditional package of liquid foundation resulted in the inconvenience of transportation and usage. In 2008, Korean skincare brand Amorepacific produced Cushion Compact [4] to solve the inconvenience. Thus customers can carry it and reapply makeup any time. The design principle was to inject liquid foundation to the sponge (cushion compact) [7] with 800 thousand air holes. To obtain the liquid foundation, customers simply press the pat. In each pressure, air will be driven into the liquid foundation. Thus it will be full of air and lighter than the normal foundation. Moreover, latex puff does not absorb water, thus, it will not attach too much powder. Lightly press the foundation onto your skin, the skin can absorb the powder, and to cover the flaws. During the developing process, the public did not accept the product widely. Turnover in the first year was only 3.8 billion Korean won (KRW). However, with the success in Korean drama in 2013, along with celebrity endorsement, subsidiaries of Amorepacific, Sulwhasoo, and Laneige sold cushion compact every 1.2 second. In 2015, cushion compacts from Amorepacific have been sold over 500 million. Among all, the biggest market is China, Taiwan, and Hong Kong. Turnovers in other compact cushion related products have risen for about $140 \%$ compared to other related products [3]. In the huge market opportunities, many cosmetic manufacturers were

\footnotetext{
Corresponding author: jordan yan@hotmail.com
} 
attracted for research and development. Owing to the fashion trend and market demand, this study aimed to develop co-cushion compact.

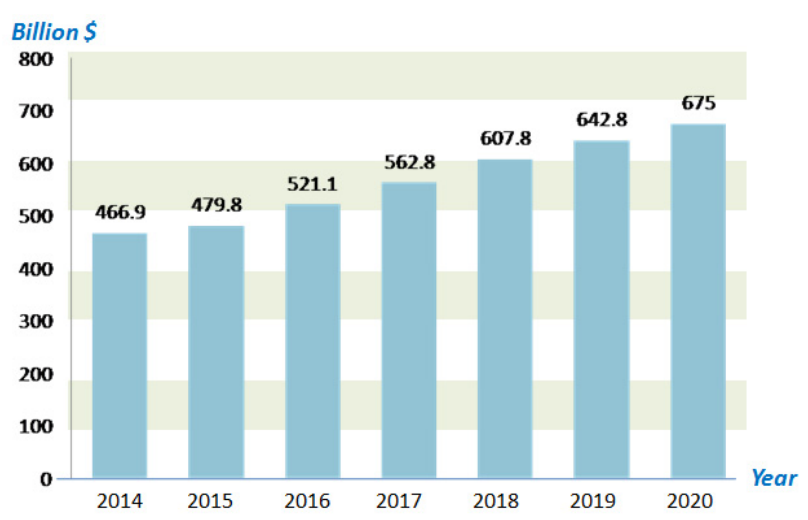

Fig. 1. Prediction for Global Cosmetic Market between 2014 to 2020.

Table 1. Cosmetic Categorization.

\begin{tabular}{|c|c|c|}
\hline \multirow{4}{*}{ 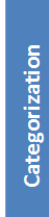 } & Item & Details \\
\hline & Cosmetics in General & $\begin{array}{l}\text { Foundation, pressed powder, lipsticks, body } \\
\text { makeup }\end{array}$ \\
\hline & Cosmetics for eyes & $\begin{array}{l}\text { Brow makeup, eye shadow, eyelid makeup, } \\
\text { mascara, eye makeup, makeup remover }\end{array}$ \\
\hline & Cosmetics for lips & Lip balm, lip gloss, lipstick, lip liner \\
\hline
\end{tabular}

\subsection{Research motivation}

Traditional liquid foundation underwent problem analysis. Figure 2 presents the problems of the traditional liquid foundation. Descriptions are illustrated in the followings.

\subsubsection{The inconvenience of transportation}

Liquid foundation in general belongs to liquid cream category. Bottles or soft tubes are normally used in packaging. To obtain the cosmetics placing in the bottles, customers simply press the lid. However, it is very likely to over squeeze due to the difficulty in controlling the proper amount of liquid. Moreover, similar problems can occur to soft tubes as well. If customers do not tighten the lid, the liquid foundation will be excreted. In terms of applying makeup onto your face, people normally collect the product in the palm of their hands and dip the finger into the liquid and smear on their face. However, this method will not provide a balanced complexion, and it will produce an uneven finish. Furthermore, skin infections may occur if hands are not properly sanitized.

\subsubsection{Cost increase in containers}

Traditional liquid foundation added some chemical synthetic for achieving specific functions such as protecting against burning, or as rejuvenation. Plastic containers are not compatible and thus corrosion might occur. Therefore, materials such as glass containers are normally used. However, the production of glass containers is high cost, and the container itself is heavier, and easily breakable. These lead to the increase cost in manufacturing.

\subsubsection{Environmental pollution issues}

Global cosmetic market grows stably every year. Regarding the ingredients and the function, the design of the package is also an important factor that consumers take into consideration when purchasing cosmetic products. Most of the consumers throw away the containers once they finish the products, which bring damage to the environment. According to the statistics calculated by the Environmental Protection Agency of USA, a quarter of landfill waste is made up of the disposable package. Thus, how to design an eco friendly package, which is reusable, is an issue that manufacturers need to face. At the same time, this is the future trend for eco cosmetics [9].

\subsubsection{Inconvenience in storage}

The amount of the liquid foundation is at least $30 \mathrm{ml}$. Therefore, for customers who use it rarely or those who use a small amount of foundation per time, liquid foundation remains a lot before it is expired or it will be
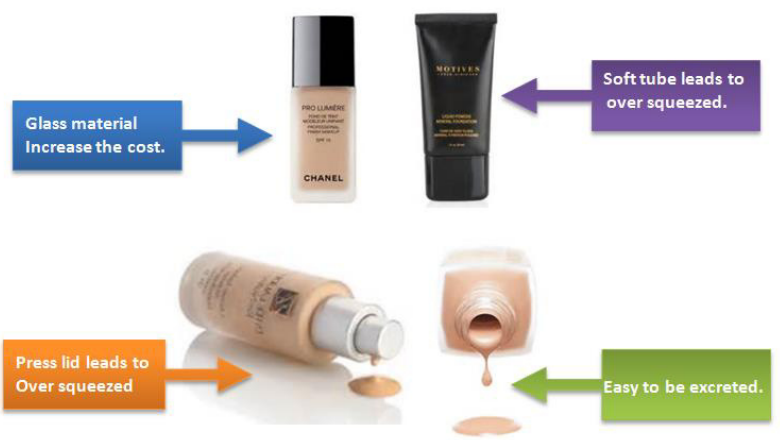

dried. Thus, it is a waste.

Fig. 2. Problem analysis of liquid foundation in the market.

Problem analysis in industrial development

(1) An appeal to safe and natural products: People pay more attention on being healthy and nurturing life. Thus, the needs for organic cosmetic markets came out. When purchasing and using cosmetics, customers bear in mind products that are healthy, safe and efficient. Products that are organic, with a few chemicals or chemical-free are the ones that customers are looking for.

(2) Need in product diversity: Cosmetics plays an important role in cosmetic industry. Cosmetics used to target female customers, and now it has caught the 
attention towards male customers. Along with the cosmetic technology and the invention of new cosmetics, cosmetic product is now approaching diverse and multiple functions. In terms of the applying time difference, there is makeup for morning, and night. Regarding the change of functions, there is makeup for sun protection, maintenance or it is water resistant. Considering the applying time, natural makeup, light makeup, outgoing makeup and so on, cosmetic is now with diverse function.

(3) Need in specific function: In the busy lifestyle, people still think highly of how they look. Cosmetics do not simply help make the skin looks better, but also provide maintenance and protection such as sun block, whitening, moisture holding, anti-aging to accord with people's need.

\subsection{Research purpose}

Based on the above problem analysis, this study invented an eco-cushion compact. Table 2 illustrated the proposed alternatives and research purpose.

Table 2. Alternatives and research purpose.

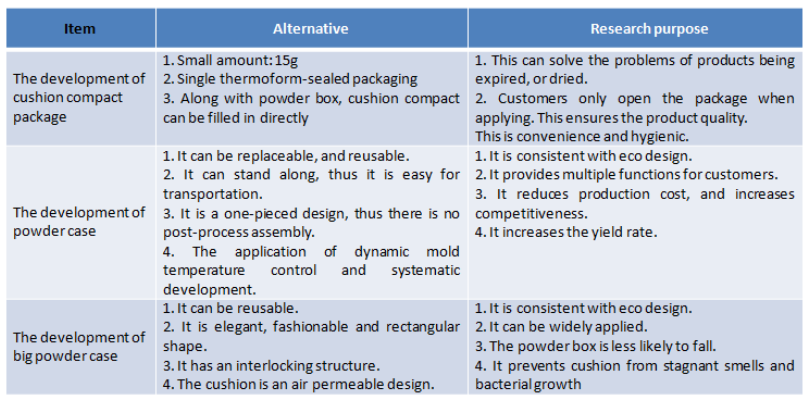

\section{Research structure}

The study was based on the existing developmental process. In addition to investigating and developing a natural multifunctional formula, the aim is to provide an eco-friendly and reusable products. The technology of mold flow analysis and dynamic mold temperature control were used to develop eco-cushion compact related products. Thus, it reduced production cost and increased the yield rate.

Figure 3 presents the flow chart of the study. The development of formula and the sample production will be described in stage 1. Mold design and production will be illustrated in stage 2 . Injection will be presented in stage 3 .

\subsection{Sample production and development}

The initial design for cushion compact was a rectangular case. The product set included the development of cushion compact case, powder case (including powder), and big powder case (including cushion and related items). The internal and external design arrangement was shown in Figure 4. The design aimed at an eco friendly and reusable design. That features are illustrated as followings.

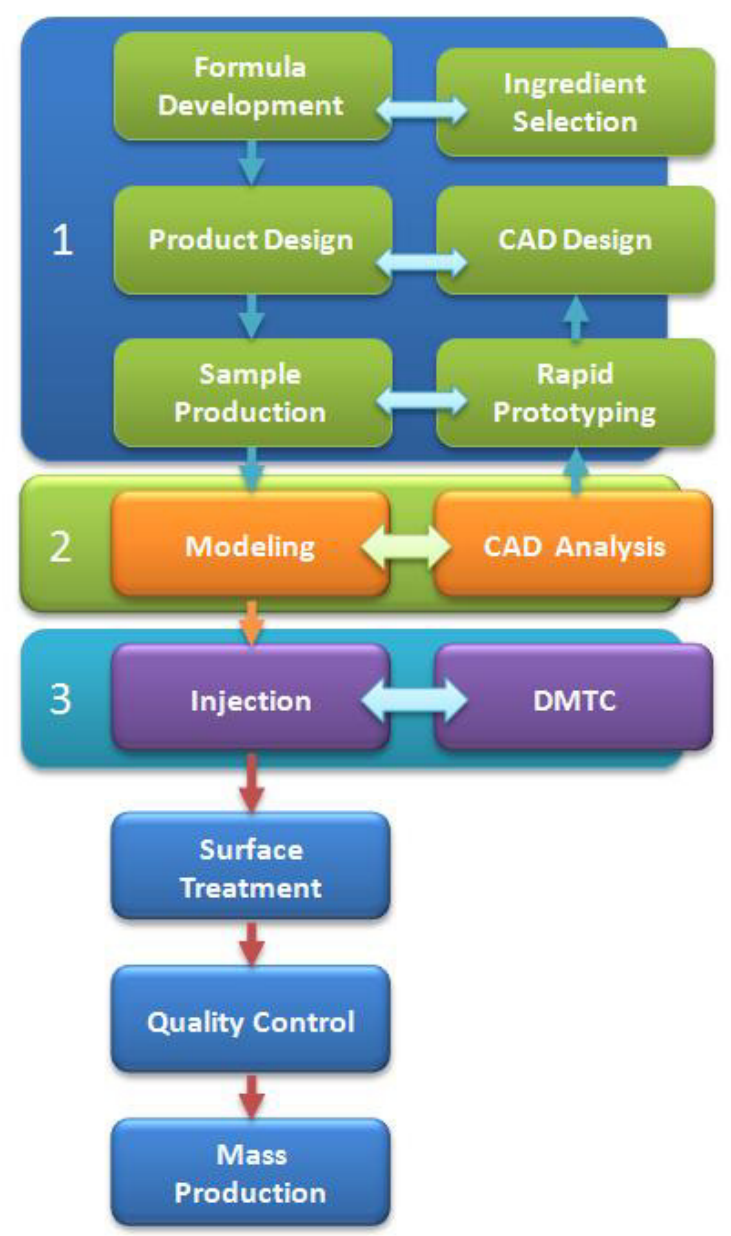

Fig. 3. Research structure and flow chart.

\subsubsection{Cushion compact case}

Cushion sponge is used to pad the powder liquid. It is a single thermoform-sealed packaging with small amount. Thus, customer can use it when they are going to use it. This ensured the product from exposing to the air and resulting in oxidation before it is used. Hence, it is fresh, and with stable quality. For products with bigger volume, it avoids product from going off due to the expiry date and provide an option for customers who use the products rarely or simply with a small amount. Figure 4(a) presents the case design and details.

\subsubsection{Powder case}

The design of the power case covered the shortcoming of traditional design. In the traditional design, it was a twoset device, and customer could not carry it outside. Now the container has changed to single package, which can stand along to carry outside. It is also reusable. In addition to providing customers multiple functions it 
accords with environmental need. It is a one-pieced design, thus, only one mold is required. Moreover, there is no post-process assembly, which reduces production cost and increases production. Figure 4(b) presents the case design and details.

\subsubsection{Powder case}

Big powder case: It is designed in an elegant rectangular shape. It is separated from the powder case to provide a clean shell. Moreover, it is reusable. The interlocking design makes it easy to remove and reseal. Furthermore, air permeable design of the cushion prevents cushion from stagnant smells and bacterial growth. Figure 4(c) presents the case design and details.

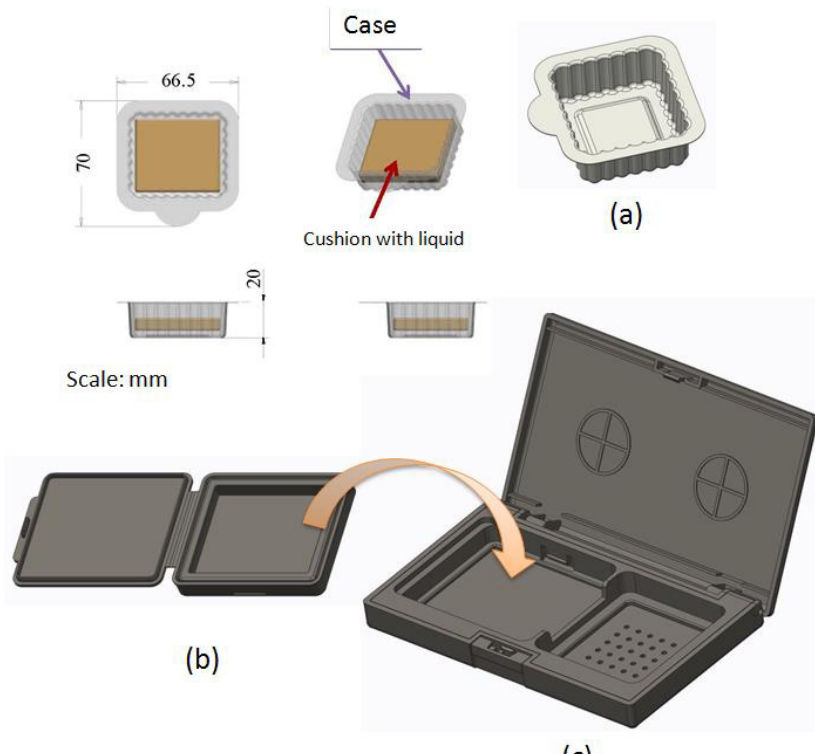

(c)

Fig. 4. The internal and external design arrangement.

\subsection{Mold design and production}

In the initial stage of developing mold for the products, mold flow was used for feasibility analysis of injection as shown in Figure 5. Through mold flow, optimal flow and cooling design [6] were observed. Thus, the maximum contraction controlled and maintained at 0.22 $\mathrm{mm}$. Hence, it ensured the air tightness of the products, and avoided spillage and drying. It also saved time used in testing, and reduced the developing time and production cost. Furthermore, it increased the product quality.

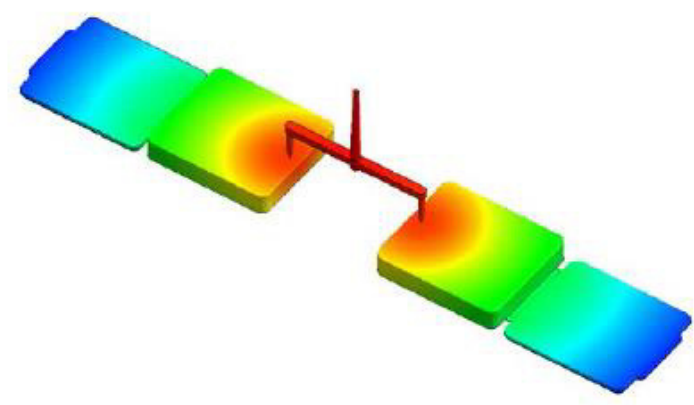

Fig. 5. Mold flow for the powder case

\subsection{Injection}

Dynamic mold temperature control was introduced $[1,2]$, plug-in mold temperature control system was designed as shown in Figure 6. Instant heating and cooling processes shortens the time for the mold to increase temperature and cooling. It shortens the injection period. Moreover, it reduces the residual stress and warping problem after the injection. This improves the surface brightness of the product, increases the product quality, accords energy saving and fulfills the market need in the green process.

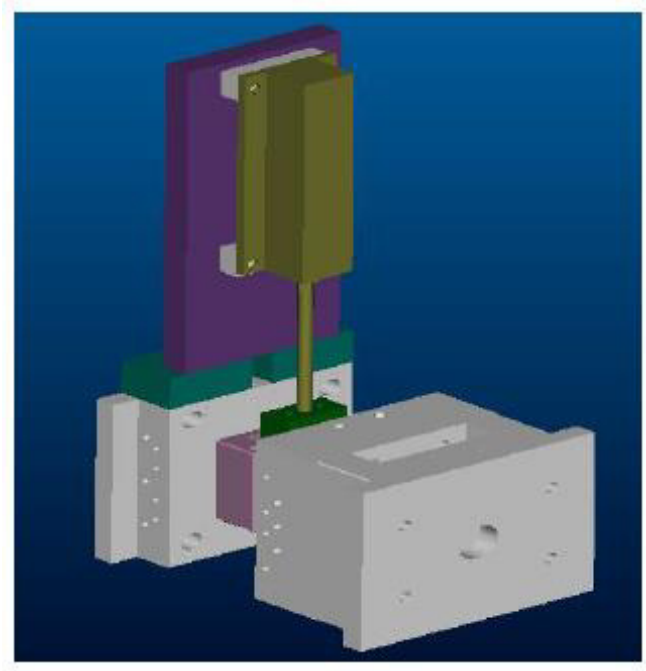

Fig. 6. Design of the dynamic mold temperature control.

\section{Research method}

\subsection{Eco product design}

Cushion compact is in the single thermoform-sealed packaging. Customer simply fills it to the powder case when applying the product. When the customer runs out of the cushion compact, they can easily placed it with a new one. Thus powder case can be reusable. The powder case is a single set design, the customer simply withdraws the case when applying, and the big powder case is less likely to be dirty. Power case is easy for transportation. Both the powder case and the big power case are reusable, which accords with eco design.

\subsection{One-pieced design of the powder case}

In the market, most of the powder cases are designed with upper and lower cases. During injection, two molds are required in manufacture along with manual assembly to complete the products. In this study, the powder case is a one-pieced design. Thus, only one mold is needed, 
and there is no post-process assembly, which reduces production cost and increases production.

\subsection{Design of the multiple functions of the big powder case}

Unlike the traditional circular design, an elegant rectangular shape was chosen to conform to customers' feel need among different countries. The internal arrangement and the clip were designed for customers to take out and utilize easily. The placement for cushion had ventilation holes, which can prevent cushion from stagnant smells and bacterial growth.

\subsection{The introduction of mold flow}

Before the development of mold, the assistant of computer analysis can be used to observe online the status of plastic in mold cavity. Thus, mold, product, and injection criterion can be modified, and the optimal design can be obtained. This saved the time used in testing, and reduced the developing time and production cost. Furthermore, it increased the product quality.

\subsection{The establishment and introduction of dynamic mold temperature control}

In the current cosmetic industry of package development, traditional injection molding is still the main stream. This method results in the difference between thickness and thinness of the products. Moreover, products are likely to be warped after the injection. Problems such as insufficient in jet flow and surface brightness also exist. Through the innovative mold temperature control technology, dynamic mold temperature control is applied to study. Figure 7 presents the advantages of the process. Before filling, the surface temperature of the mold is heated to glass transition temperature. This increased the fluidity of melt in the mold, decreased the injection pressure, and cutting force during the melt filling process. Furthermore, it reduced the residual stress and warping problem and increased the stability of the case. It avoided spillage and drying and at the same time, it shortened the injection period and increased the surface brightness of the product, the yield rate. This is a green technology.

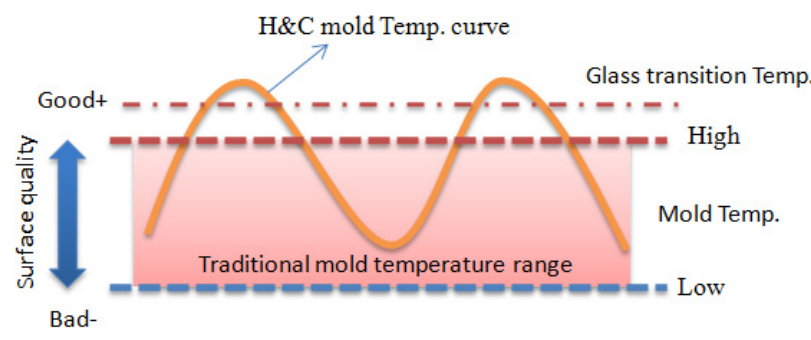

Fig. 7. H\&C mold temperature curve and glass transition temperature.

\subsubsection{Dynamic mold temperature control, DMTC}

Dynamic mold temperature control has advantages such as improving product quality and shortening injection period. This technology includes "internal mold heating temperature controlling technology" and "mold surface heating temperature controlling technology". There are various ways of heating. After comparison between disadvantages and advantages, it can be seen that mold surface heating temperature controlling technology has higher heating efficiency and the ability to save energy.

Induction Heating Temperature Control, IHTC, adopted different types of induction coils for rapid heating on mold surface. This eliminates defects from the product such as surface stitch line and contraction. The feature of the technology is superficial heat of the mold surface, which is about $0.1 \mathrm{~mm}$. It resulted in rapid change of the temperature on the mold, which is about 20-40 degree Celsius. It was used to approach mold surface for heating. After designing, the system is able to heat both singlesided and double-sided mold. Infrared halogen lamp can operate vertical move, which is presented in Figure 8. Structure and related design of the temperature controlling set and injection machine is also shown in the Figure 8.

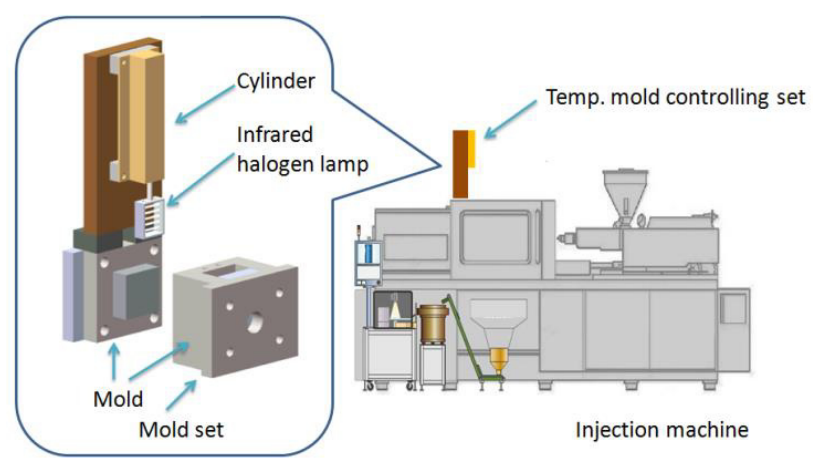

Fig. 8. Application and design of the combination between induction dynamic mold temperature control and injection machine.

Application of the rapid temperature control on the mold surface is an important technology in advanced injection field. Rapid heating does not influence the injection period. Low heating energy is used, thus it accords with green technology. Moreover, superficial heating of the surface mold does not lead to thermal expansion of the overall mold. Hence, it won't influence its usable life. On the other hand, in terms of mold cooling, to achieve the goal of rapid cooling, surface heating provided low heat energy to the mold. Thus, cooling process is faster. The freedom of the future temperature control technology can be increased efficiently. 


\section{Results and discussion}

Results that were referred to green manufacture are described as follow.

\subsection{Energy efficiency increased}

It reduced $10 \%$ of the injection period, and yield rate of the product was over $95 \%$. Moreover, it reduced the cost of manpower and saved mechanical energy. Temperature control of the traditional injection mold had strong influence towards product injection period and surface quality. Surface mold with high temperature is good quality; however it is very likely to be warped, as shown in Figure 9 (a). Introduction of dynamic mold temperature control increased the fluidity of melt in the mold and the heating efficiency. Moreover, it decreased the injection pressure, $10 \%$ of the injection period and increased the product size stability. In addition, it improved the appearance, and increased the yield rate to over 95\%, as shown in Figure 9 (b).

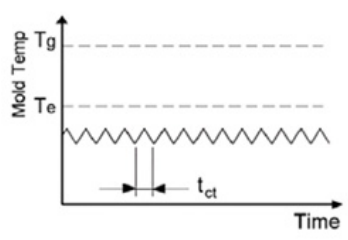

(a)

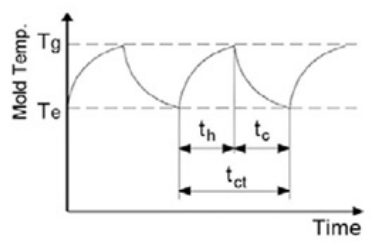

(b)
Fig. 9. Comparison of injection period between traditional injection and dynamic mold temperature control.

\subsection{Material reduced}

It reduced over $20 \%$ of the plastic material and over $40 \%$ of the metal material for the mold. The traditional powder case includes two set of mold as shown in Figure 10 (a). After manual assembly, post-process assembly is required for cosmetic filling process. In this study, the powder case is a one-pieced design, as shown in Figure 10 (b). Thus, only one mold is needed, and manual assembly is not needed, which reduces materials, mold cost and manual cost
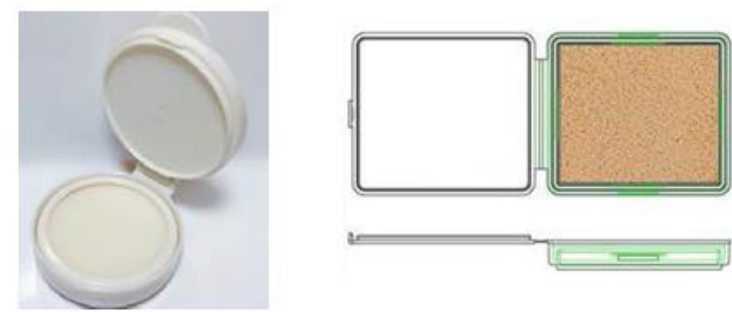

Fig. 10. Comparison of injection period between traditional injection and dynamic mold temperature control
Table 3 illustrates concrete results of the injection; meanwhile current technology and industrial condition are discussed.

Table 3. Advantage and improvement of the injection under DMTC

\begin{tabular}{|c|c|c|}
\hline & Before & After \\
\hline 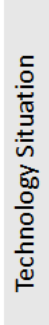 & $\begin{array}{l}\text { Thickness and thinness } \\
\text { difference of the powder case } \\
\text { products and imbalance control } \\
\text { of the mold temperature } \\
\text { influence product injection } \\
\text { quality. Long injection period } \\
\text { leads to wrapped products for } \\
\text { over } 0.05 \mathrm{~mm} \text {. Worse air } \\
\text { tightness, air leakage is over } \\
8 \% \text {. Powder is very likely to spill } \\
\text { or dry. }\end{array}$ & $\begin{array}{l}\text { The development of dynamic mold } \\
\text { temperature control reduced } \\
\text { injection period, and residual stress. } \\
\text { Warping problem is reduced to less } \\
\text { than } 0.2 \mathrm{~mm} \text {. The increase of the air } \\
\text { tightness leads to less than } 2 \% \text { of } \\
\text { the air leakage. Injection period is } \\
\text { decreased at least } 10 \% \text {. }\end{array}$ \\
\hline 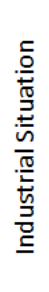 & $\begin{array}{l}\text { Traditional injection cannot } \\
\text { satisfy the rapid change of the } \\
\text { industry. Considering manual } \\
\text { cost and labor needs, most of } \\
\text { the factories are set in China, or } \\
\text { Vietnams. There is not much } \\
\text { difference in products } \\
\text { compared to its competitors. } \\
\text { Hence, price cannot be raised } \\
\text { to create higher income. }\end{array}$ & $\begin{array}{l}\text { Dynamic mold temperature control } \\
\text { is now developing in the country. } \\
\text { Introducing the new technology is } \\
\text { beneficial to future product } \\
\text { competiveness and industrial } \\
\text { development. }\end{array}$ \\
\hline
\end{tabular}

\section{Acknowledgement}

The authors are grateful to the Ministry of Economic Affairs of Taiwan for supporting this research under CITD, Grant No. E10500006011-274.

\section{References}

1. D. Yao, B. Kim, Development of rapid heating and cooling system for injection molding applications, Polymer Engineering and Science, 42(12), pp. 24712481, (2002)

2. P. C. Chang, S. J. Huang, Simulation of infrared rapid surface heating for injection molding, International Journal of Heat and Mass Transfer, pp. 3846-3854 (2006)

3. http://www.harpersbazaar.com/beauty/makeup/g732 7/best-cushion-compacts- summer-skin/

4. http://www.glamour.com/story/how-to-use-cushioncompact-foundation

5. http://www.researchandmarkets.com/reports/404019 6/global-organic-cosmetics-market-forecast-and

6. D. Pierick, R. Noller, The effect of processing conditions on shrinkage, Society of Plastics Engineers, ANTEC, pp. 252-258, (1991)

7. Huh, J. W., Choi, K. H., \& Jue, M. S. The accuracy of ultrasonography on the location of lipomas in the 
forehead, Program book (old book collection), 67(2), pp. 443-444 (2015)

8. Tundis, R., Loizzo, M. R., Bonesi, M., \& Menichini, F. Potential role of natural compounds against skin aging. Current medicinal chemistry, 22(12), pp. 1515-1538 (2015)

9. Philippe, M., Didillon, B., \& Gilbert, L. Industrial commitment to green and sustainable chemistry: using renewable materials \& developing ecofriendly processes and ingredients in cosmetics. Green Chemistry, 14(4), pp. 952-956 (2012) 